\title{
Trasplante experimental de islotes de páncreas en el tracto genitourinario asociado al trasplante renal
}

\author{
Gómez Dos Santos V11, Burgos Revilla FJ ${ }^{2 A}$, Pascual Santos J³, Marcen Letosa R ${ }^{3 A}$, \\ Villafruela Gómez JJ33, Correa Gorospe $\mathrm{C}^{4}$, Cuevas Muñoz B ${ }^{4}$, Mampaso FA, García Gonzalez R \\ ${ }^{1}$ Unidad de Urología. Fundación Hospital Alcorcón. ${ }^{2}$ Servicio de Urología, ${ }^{3}$ Nefrología, ${ }^{4}$ Investigación y \\ ${ }^{5}$ Anatomía Patológica. Hospital Ramón y Cajal. ${ }^{A}$ Universidad de Alcalá. Madrid.
}

Actas Urol Esp. 2008;32(1):102-118

\section{RESUMEN}

TRASPLANTE EXPERIMENTAL DE ISLOTES DE PÁNCREAS EN EL TRACTO GENITOURINARIO ASOCIADO AL TRASPLANTE RENAL

Conceptualmente el trasplante de páncreas (TP) asociado al trasplante renal (TR) puede resolver la insuficiencia renal crónica (IRC) y la diabetes (DM). Aunque el lugar de implantación más frecuentemente utilizado es la vena porta, el tracto genitourinario puede ser adecuado desde un punto de vista técnico durante el TR.

20 animales con una edad media de 5,5 (SD 1,1) meses y una mediana de peso de $53(30,102) \mathrm{kg}$ se sometieron al siguiente protocolo experimental. El primer día, se lleva a cabo la nefrectomía izquierda y el injerto es perfundido con solución de Wisconsin, lo que se sigue de una pancreatectomía distal y el aislamiento de islotes por medio de la digestión enzimática con Colagenasa. Los islotes son teñidos con el colorante vital Ditizona (DTZ) y cultivados durante 24 horas a $37^{\circ}$ y $5 \%$ de $\mathrm{Co}_{2}$. El día 2 se realiza la nefrectomía derecha y un TR ortotópico del injerto renal izquierdo preservado. Los islotes son trasplantados en 4 localizaciones diferentes en el tracto genitourinario: el espacio subcapsular del injerto renal, en la submucosa de vejiga, en el parénquima testicular y por vía deferencial. El día 7 , los animales son sacrificados para estudio histopatológico.

Se demostraron islotes viables en la submucosa vesical y en el testículo tras infusión por vía deferencial.

Palabras clave: Trasplante de islotes pancreáticos. Modelos experimentales.

\section{ABSTRACT \\ EXPERIMENTAL PANCREATIC ISLET TRANSPLANT INTO THE GENITO-URINARY TRACT SIMULTANEOUS TO KIDNEY TRANSPLANT}

Introduction and objectives: Simultaneous kidney and pancreas transplant is a good treatment for both renal and pancreas insufficiency. Experimental apply of genitourinary tract for pancreas implantation is reported in this work.

Material and method. Twenty animals aged as average 5.5 monts (SD 1.1) and an average weight of $53 \mathrm{kgr}$ were submitted to this protocol. In the day 1 a left nephrectomy is completed and the graft is perfused with University of Wisconsin solution. A partial pancreatectomy is completed at following, isolation of pancreatic islets by colagenase enzymatic digestion. Islets are dryed with Ditizone and culptured for 24 hours at $37^{\circ} \mathrm{C}$ and $5 \%$ CO2. Day-2 a right nephrectomy is performed and orthotopic renal autotransplant using the left kidney is completed. Pancreatic islets are transplanted in 4 different locations of the genitourinary tract: renal subcapsular space, bladder submucosae, testis parenchyma and vas deferens. Day-7, all the animals were sacrifized to complete pathological study.

Results and conclusions: Viable islets were isolated in bladder submucosae and testis after transdeferential injection.

Keywords: Pancreatic islets transplant. Experimental models. 
$\mathrm{L}$ a Asociación Americana de Diabetes (American Diabetes Association, ADA) ha revisado los criterios diagnósticos de diabetes y recomendado su clasificación según los términos tipo 1 o con deficiencia de insulina y tipo 2 en los que no se evidencia una deficiencia severa de insulina. La diabetes tipo 1 a su vez se subclasifica en tipo $1 \mathrm{~A}$ o mediada inmunológicamente y tipo $1 \mathrm{~B}$ o no inmune lo que tiene relevancia desde el punto de vista de su tratamiento ${ }^{1}$.

La diabetes tipo 1 es el resultado de la destrucción de las células beta productoras de insulina pancreáticas. Su incidencia es muy variable entre diferentes poblaciones aunque con una tendencia uniforme a su incremento a nivel mundial que se puede calcular en un 3-4\% interanual. La patogénesis de la enfermedad parece conllevar la interrelación de una susceptibilidad genética de naturaleza poligénica y factores ambientales entre los que se han implicado infecciones víricas, factores dietéticos en edades tempranas, tóxicos, vacunas o factores psicológicos sin que, en ninguno de los casos, se haya puesto de manifiesto una relación causa ${ }^{1-5}$.

La población con diabetes presenta un riesgo elevado de desarrollo de macro y microangiopatía como consecuencia de los cambios del metabolismo de los carbohidratos que son responsables de las principales complicaciones a largo plazo de la enfermedad. La microangiopatía es la responsable de las retinopatía, neuropatía vegetativa y somática y nefropatía ${ }^{6,7}$.

Aunque la etiología de la insuficiencia renal crónica (IRC) en el paciente diabético es múltiple, la primera causa es la nefropatía diabética, definida como la presencia persistente de microalbuminuria sin otra enfermedad renal. Se trata de una manifestación relativamente tardía de la enfermedad renal y con frecuencia se acompaña o es seguida en poco tiempo por el desarrollo de HTA y deterioro de la función renal. La prevalencia de IRC en pacientes diabéticos tipo 1 alcanza 30-40\%. La diabetes representa en el momento actual la primera causa de IRC en EEUU, con una prevalencia en torno al $30 \%$. En nuestro entorno y según datos del Registro de la Asociación Europea de Diálisis y Trasplante (EDTA) la prevalencia se estima en un 14\%. En EEUU, Japón y Norte de Europa la nefropatía diabética es más frecuentemente consecuen- cia de diabetes tipo 1, por el contrario en el Centro y Sur de Europa la causa más frecuente de nefropatía diabética es la diabetes tipo 2. El trasplante renal constituye la mejor alternativa terapéutica en estos pacientes; sin embargo, no resuelve el trastorno metabólico subyacente por lo que no evita el desarrollo del resto de las complicaciones de la enfermedad ni previene la recidiva de la nefropatía en el injerto, lo cual hace deseable la asociación del trasplante de tejido pancreático que permitiría la resolución del trastorno metabólico sin incrementar de modo significativo la morbi-mortalidad del $\mathrm{TR}^{8-11}$.

\section{TRASPLANTE DE TEJIDO PANCREÁTICO}

El trasplante de tejido pancreático puede realizarse en forma de órgano vascularizado o como un injerto libre de células beta, lo que desde un punto de vista teórico supone una alternativa muy atractiva al disminuir la morbi-mortalidad en el paciente.

\section{TRASPLANTE DE PÁNCREAS}

Desde que en 1966, en la Universidad de Minnesota, se llevó a cabo el primer trasplante de páncreas (TP) hasta diciembre de 2004 se ha comunicado al Registro Internacional de Trasplante de Páncreas (International Páncreas Transplant Registry, IPTR) la realización de 23.043 trasplantes de órgano que incluyen 17.127 realizados en EEUU y casi 6.000 en el resto de países con programa de trasplante pancreático ${ }^{12}$ (Fig. 1).

La necesidad de inmunosupresión mantenida que resulta en morbi-mortalidad cardiovascular y un incremento en la incidencia de infecciones, neoplasias y procesos linfoproliferativos, es la responsable de que hasta el $75 \%$ de los TP se realicen de forma simultánea con un TR en pacientes con diabetes tipo 1 con IRC (Figs. 2 y 3).

En el trasplante simultáneo páncreas-riñón (SPK, simultaneus páncreas kidney), el origen del injerto pancreático suele ser un donante cadáver común para el injerto renal. Sin embargo, existen otras opciones que permiten el trasplante simultáneo, como el donante vivo renal que se mantiene en espera hasta la obtención de un donante cadáver pancreático o la obtención simultánea de donante vivo del injerto renal y del injerto segmentario 


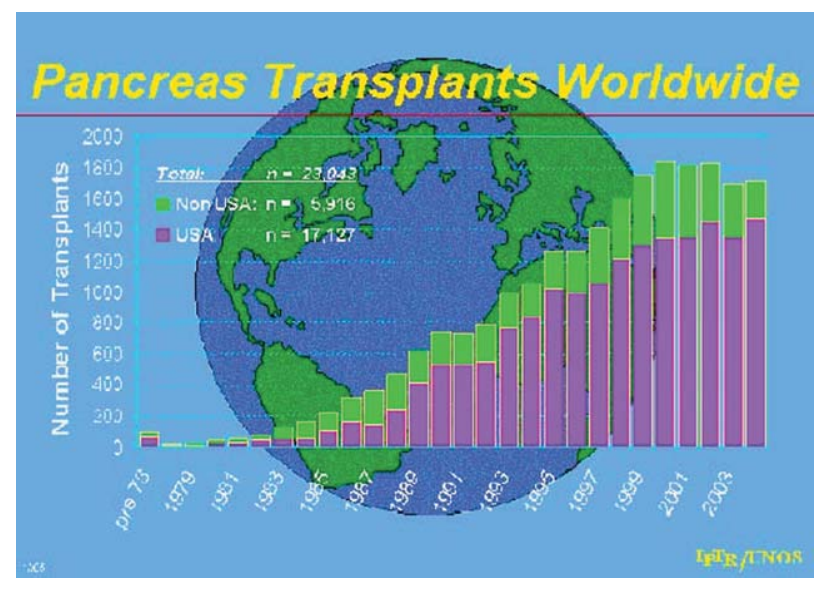

FIGURA 1. Número de Trasplantes de Páncreas a nivel mundial. Tomado de "International Pancreas Transplant Registry (IPTR)" con base en la Universidad de Minnesota. EEUU 2003.

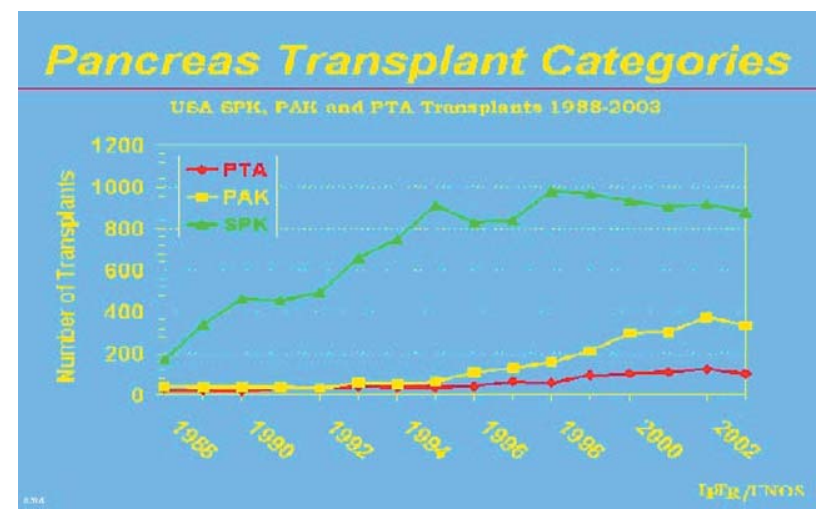

FIGURA 2. Número de Trasplantes de Páncreas en EEUU clasificados por categorias. PTA: Trasplante Aislado de Páncreas. PAK: Trasplante de páncreas posterior a Trasplante renal. SPK: Trasplante simultáneo páncreasriñón. Tomado de "International Pancreas Transplant Registry (IPTR)" con base en la Universidad de Minnesota. EEUU. 2003.

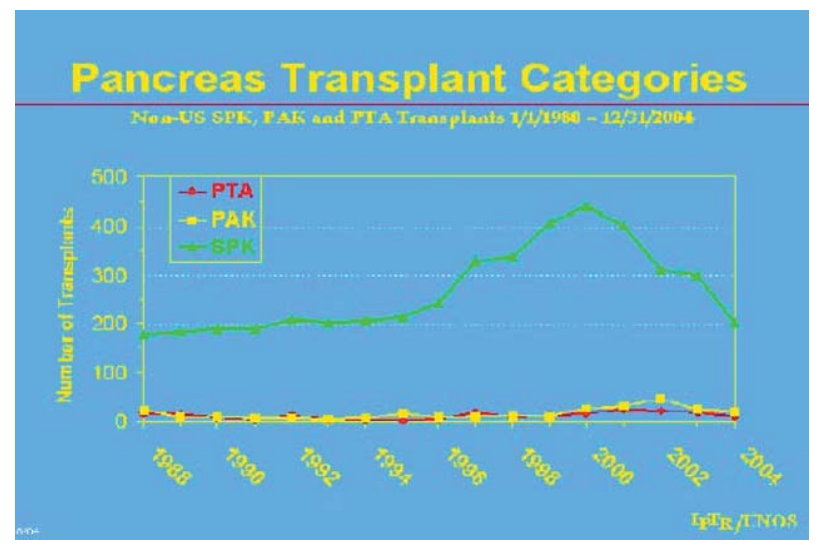

FIGURA 3. Número de Trasplantes de Páncreas fuera de EEUU clasificados por categorias. Tomado de "International Pancreas Transplant Registry (IPTR)" con base en la Universidad de Minnesota. EEUU. 2003. pancreático. Los resultados obtenidos con los diversos procedimientos alcanzan supervivencias al año del 94\% y del 86\% para los injertos renal y pancreático respectivamente ${ }^{12,13}$.

Aunque los resultados del TP han mejorado dramáticamente después de 1998 con la introducción de nuevos inmunosupresores, los resultados del TP en el paciente de un injerto renal funcionante (PAK, páncreas after kidney) y del injerto pancreático aislado (PTA, páncreas trasplant alone) aún no son equivalentes a los del SPK. La supervivencia del injerto en el PAK alcanza un 74\% y sólo un $68 \%$ en el PTA. Esta última forma de trasplante se restringe al paciente con diabetes tipo 1 muy inestable con episodios múltiples de hipoglucemia que comprometan su vida. E1 paciente debe conservar una función renal que le permita tolerar la nefrotoxicidad de las potentes pautas de inmunosupresión empleadas. Hasta un $10 \%$ de los pacientes sometidos a PTA, en algunas series, requieren un TR posterior ${ }^{12-14}$.

En el momento actual el TP es el único tratamiento con capacidad para reestablecer consistentemente un estado de insulin-independencia representado por una glucemia normal y determinaciones de hemoblobina glicosilada, a su vez, normales o muy próximas a la normalidad. El paciente recupera la respuesta normal de liberación de insulina frente a la estimulación tanto oral como intravenosa a la glucosa si bien la concentración de insulina en sangre periférica en respuesta a la estimulación es 2 ó 3 veces superior a la normal. El estado de hiperinsulinemia es consecuencia del drenaje venoso sistémico del injerto y de la resistencia periférica a la insulina inducida por el uso de corticoides como inmunosupresores. El estado de contrarregulación de la glucosa también mejora tras el TP debido a la normalización de la secreción de glucagón en respuesta a la hipoglucemia así como de la respuesta de la secreción de adrenalina y por tanto del reconocimiento por parte del paciente de los sintomas de hipoglucemia ${ }^{15,16}$.

Los resultados alcanzados en el control metabólico y de las complicaciones a largo plazo en el paciente diabético hacen, en el momento actual, posible la recomendación del TP en aquel paciente con IRC que obliga a un TR y por tanto a su inmunosupresión crónica sin que el trasplante simultáneo o posterior de un injerto pan- 
creático incremente significativamente la morbimortalidad del procedimiento. Por ello es esencial la selección estricta del receptor, esto es de pacientes jóvenes (menos de 50 años) y sin cardiopatía isquémica significativa, ya que ésta constituye la primera causa de mortalidad en este grupo.

En ausencia de necesidad de un TR el TPA sólo se recomendará en aquellos pacientes con una historia de complicaciones metabólicas agudas frecuentes y severas que requieran atención médica y que supongan el fallo reiterado de un régimen intensivo de tratamiento insulínico.

\section{TRASPLANTE DE ISLOTES PANCREÁTICOS}

En este contexto, conceptualmente el trasplante de islotes de páncreas (TI) conllevaría ventajas potenciales muy significativas ${ }^{17}$.

La glándula pancreática está constituida por, aproximadamente un 3\% de tejido endocrino, los llamados islotes pancreáticos de Langerhans, cuyo número se calcula en torno a $1 \times 10^{6}$ en el páncreas humano normal. Cada islote está formado por 4 tipos celulares: alfa, beta, gamma y células PP; cada una de las cuales posee una función. Las células alfa secretan glucagón, cuya función es estimular la glucogenolisis y la movilización de glucosa desde el hígado. Las células beta, productoras de insulina, por el contrario disminuyen la producción de glucosa por el hígado e incrementan la captación de la misma por tejidos periféricos. Las células gamma producen somatostatina que regula la producción de glucagón e insulina. Las células PP, productoras del polipéptido pancreático, poseen una función desconocida hasta el momento. El correcto control metabólico depende de la función integral del islote y no de la liberación exclusiva de insulina ${ }^{1}$.

Conceptualmente, los objetivos de insulin independencia y prevención de complicaciones secundarias de la diabetes pueden lograrse mediante el trasplante selectivo del tejido endocrino. Las ventajas potenciales sobre el trasplante de órgano incluyen una morbilidad quirúrgica menor, la posibilidad de retrasplante en caso de fracaso del injerto, evitar las complicaciones asociadas con el componente exocrino pancreático y la posibilidad de disminuir la inmunogenicidad del injerto mediante técnicas de inmunoaislamiento o de inducción de tolerancia inmune en el receptor que eliminase la necesidad de inmunosupresión y potenciase el trasplante en fases tempranas de la evolución de la diabetes ${ }^{17}$.

En 1967, Lacy y Kostianowsky describen la primera técnica de digestión pancreática mediante distensión intracanalicular, disrupción mecánica manual del tejido e incubación en solución de colagenasa. El modelo fue progresivamente perfeccionado hasta la descripción en 1988 por Ricordi de un procedimiento de digestión automatizada cuyo objetivo era disminuir el traumatismo mecánico a que son sometidos los islotes a través de un proceso de digestión continuo que permitía la liberación progresiva de los islotes del tejido exocrino ${ }^{18}$. Un año más tarde, en 1989, el mismo método automatizado es aplicado a un modelo humano de aislamiento ${ }^{19}$ que incrementó significativamente las tasas de aislamiento y condujo al logro de los primeros casos bien documentados de insulin-independencia en el modelo humano y por lo tanto al establecimiento durante la década de 1990 de ensayos clínicos, cuyos resultados han sido recogidos en el Registro Internacional de Trasplante de Islotes.

El TI, actualmente, como en sus inicios, se enfrenta aún a 4 dificultades básicas que limitan su efectividad: el aislamiento y purificación del componente endocrino; la preservación; el lugar óptimo de implantación y los fenómenos de rechazo alo y autoinmune.

\section{Aislamiento y purificación}

Después de 3 décadas de desarrollo, la obtención de una masa adecuada de islotes procedentes de un único donante para su implante en un receptor continúa siendo un factor limitante de la técnica y aunque actualmente se dispone de procedimientos de digestión y purificación prácticamente automatizados y que consiguen el aislamiento de islotes con un elevado grado de purificación, los efectos biológicos deletéreos de ambos procesos son conocidos y motivo de continua controversia ${ }^{20,21}$.

El primer problema que nos encontramos en el proceso de aislamiento, es la elección de un donante adecuado. La presencia de episodios de hipotensión prolongados durante el periodo de 
mantenimiento del donante, estados de hiperglucemia en el cadáver, el desarrollo de parada cardíaca y la duración de la isquemia fría afectan negativamente la tasa de aislamiento ${ }^{22}$.

Todos los métodos de aislamiento conllevan la digestión enzimática de la glándula con colagenasa con o sin disrupción mecánica asociada seguida de su lavado por centrifugación lo que permite la obtención de un pellet no purificado de islotes y tejido acinar. En este proceso, la principal fuente de variación hasta este momento en el procesamiento de la glándula viene determinada por la efectividad de la colagenasa utilizada en la digestión. La colagenasa más comúnmente utilizada es una enzima obtenida del Clostridium histolitycum, cuya actividad varía ampliamente determinando la masa de islotes obtenidos. La introducción de la Liberasa, una mezcla conocida de enzimas purificadas ha resuelto parcialmente el problema incrementando la tasa de aislamiento y la función de los islotes en los tests in vitro. Los métodos de digestión utilizados en la actualidad, aunque se basan en la técnica automatizada desarrollada por Ricordi aún requieren de la intervención humana para decidir el momento óptimo en el que debe cesar el proceso de digestión introduciendo por lo tanto un elemento de subjetividad $^{20,21,23-30}$.

La purificación de los islotes respecto al tejido acinar es otro paso del aislamiento que no es solamente complejo técnicamente sino que supone un significativo impacto en la masa final de islotes obtenida y continúa siendo motivo de controversia ${ }^{31}$. La justificación de la purificación ha residido en la creencia de que la inmunogenicidad del tejido trasplantado residía exclusivamente en el tejido exocrino y linfoide contaminantes. La capacidad inmunogénica inherente al tejido endocrino demostrada y la posibilidad de recidiva de la respuesta autoinmune hacen necesaria la inmunosupresión del receptor y no justificarían la purificación.

La defensa de la purificación supone asumir que el islote aislado conserva su capacidad integra de funcionamiento y supervivencia e ignorar la existencia de mecanismos de regulación autocrinos y paracrinos en la estructura altamente organizada del islote pancreático, cuyo sistema de microcirculación portal ha sido ampliamente descrito y de cuya reproducción en el lugar ectópico de implante depende su supervivencia.

Los métodos de purificación más ampliamente utilizados se basan en el establecimiento de gradientes de densidad. La eficacia relativa del procedimiento depende, en primer lugar, de la falta de homogeneidad de tamaño, tanto de los islotes como del tejido acinar, obtenidos de la digestión enzimática y que se usa como parámetro de separación y en segundo lugar de la modificación de la densidad del tejido acinar secundaria al edema celular que sucede durante el procesamiento del tejido. Otro motivo en contra de la purificación puede estar constituido por la demostración de la existencia de precursores de células beta en el componente acinar que podrían suponer el potencial de crecimiento del islote implantado in vivo ${ }^{32,33}$.

El resultado final es la pérdida de hasta el $50 \%$ de los islotes obtenidos en la digestión.

\section{Preservación}

La solución de Wisconsin ha demostrado ser, hasta el momento y uniformemente, en todos los modelos animales y en el humano la más adecuada para la preservación de la glándula pancreática durante la extracción y hasta el momento de llevar a cabo el aislamiento de los islotes con recuentos sistemáticamente elevados. Los mejores resultados se han obtenido con tiempos de preservación inferiores a 8 horas. En 1989 se introdujo la conocida como preservación en 2 capas que permite la perfusión continua con $\mathrm{O} 2$ de la glándula que permanece en un medio con perfluorocarbono ${ }^{34-36}$.

\section{Lugar de implantación}

El lugar óptimo de implantación requiere accesibilidad, adecuada perfusión tisular y obtención de factores tróficos del tejido circundante que permita la función a largo plazo de los islotes. Ninguno de los lugares de implantación heterotópica ensayados hasta el momento han demostrado su idoneidad. Hasta el momento los únicos lugares que se han demostrado eficaces han sido la implantación hepática intraportal y la implantación esplénica. Se pueden considerar 2 grupos de lugares de implantación en base al drenaje venoso: sistémico o portal. El drenaje 
venoso portal parecería ventajoso frente al sistémico ya que éste consigue la normoglucemia a expensas de un estado de hiperinsulinemia. Entre los lugares de implantación con drenaje venoso sistémico se han ensayado: el espacio subcapsular renal, los tejidos subcutáneo y muscular esquelético, el timo, el testículo y el espacio intratecal. Entre los lugares de implantación con drenaje portal se encuentran: el hígado, el bazo, la cavidad peritoneal, el epiplón y el espacio submucoso de los tractos digestivo alto y anorrectal.

Los lugares de implantación más accesibles, tejidos subcutáneo ${ }^{37}$ y muscular esquelético, han mostrado su inviabilidad como consecuencia de la pobre perfusión tisular y casi ausente implantación de los islotes. El espacio subcapsular renal $^{38,39}$ muestra, por el contrario, una rica vascularización a expensas de las arterias capsulares, sin embargo, requiere un acceso quirúrgico que limita su utilidad en el TI como proceso aislado no asociado al trasplante hepático o renal, por otro lado los resultados en humanos no han sido tan prometedores como en modelos animales. El implante intratímico ${ }^{40,41}$ proporciona, junto con la accesibilidad, la protección del injerto frente a la respuesta inmune. La presencia intratímica del aloinjerto desarrolla cierto grado de tolerancia inmunológica por parte de los timocitos en maduración frente a los antígenos del donante. El testículo ${ }^{42,43}$ se ha considerado clásicamente un lugar inmunoprivilegiado que permite la supervivencia prolongada de diversos aloinjertos tisulares, para lo cual se ha propuesto como mecanismo la expresión por parte de las células de Sertoli del ligando Fas (FasL) que se une al receptor Fas en células $\mathrm{T}$ e inhibe su respuesta inmune. Diversos autores han ensayado el implante de islotes en el espacio intratecal ${ }^{44,45}$ demostrándose su viabilidad, con supervivencias prolongas de alo y xenoinjertos. En la clínica, sin embargo, el acceso muestra claras dificultades que podrían ser resueltas con la instalación de un dispositivo integrado en un conducto de derivación ventrículo-peritoneal modificado. El carácter de lugar inmunoprivilegiado del espacio intratecal es controvertido y requiere la integridad de la barrera hematoencefálica. La implantación hepática mediante infusión intraportal ${ }^{46}$ ha sido ampliamente ensayada en el ámbito experi- mental y clínico; reúne las ventajas de proporcionar adecuada vascularización y viabilidad del implante, siendo así mismo accesible por punción percutánea. El implante esplénico ${ }^{47}$ se ha realizado tanto en su espacio subcapsular como por inyección directa o canulación de los vasos hiliares, los dos últimos procedimientos con claros riesgos hemorrágicos. El espacio submucoso $^{48-51}$ de los tractos gastrointestinal alto y anorectal proporcionan una abundante vascularización con drenaje venoso portal y la posibilidad de realizar el implante con control endoscópico, así como accesibilidad para su control y biopsia en el seguimiento. Finalmente, el espacio intraperitoneal $^{52}$ presenta requerimientos elevados de volumen tisular implantable para revertir el estado diabético.

Los métodos de exclusión inmunológica atienden al principio de separar los islotes del medio interno del receptor por interposición de una membrana artificial semipermeable que permita la difusión de moléculas de bajo peso molecular, como nutrientes e insulina, impidiendo el acceso a anticuerpos o células ${ }^{53,54}$. Los ensayos clínicos con dispositivos de exclusión inmunológica han presentado un éxito parcial, limitado por las características físicas de las membranas y su biocompatibilidad.

\section{Control del rechazo alo y autoinmune}

Tras su trasplante, los islotes pueden ser destruidos por 3 mecanismos: la respuesta inflamatoria inespecífica, el rechazo antígeno específico y la recurrencia de la respuesta autoinmune.

La respuesta inflamatoria parece mediada por citokinas como la inteleukina 1 (IL-1), el factor de necrosis tumoral alfa (TNF-alfa) y el interferón gamma (INF-gamma) que estimulan la producción de radicales libres de oxígeno en una variedad de células, fundamentalmente macrófagos y a las que son extremadamente vulnerables las células beta. El importante contenido retículoendotelial del hígado, representado por las células de Kupfer, podría explicar que se calcule que sólo un $30 \%$ de la masa de islotes trasplantada por infusión portal se implante finalmente.

En ausencia de mecanismos efectivos de inducción de un estado de inmunotolerancia, la inmunosupresión a largo plazo es obligada para 
proteger el injerto de las respuestas alo y autoinmune. La inmunosupresión convencional ha demostrado un amplio potencial diabetogénico secundario a toxicidad sobre el islote y a resistencia periférica a la insulina.

Los glucocorticoides no sólo inducen resistencia periférica a la insulina, sino que se han demostrado capaces de disminuir la secreción de la misma.

La CSA, un inhibidor de la calcineurina que bloquea la transcripción del gen del receptor de la IL-2 y por lo tanto la activación subsecuente de células $\mathrm{T}$, disminuye la secreción de la insulina como resultado probablemente de la interferencia con el funcionamiento de canales de calcio voltaje dependientes, mecanismo común con el inmunosupresor tacrolimus.

El micofenolato mofetil es un inhibidor de la sintesis de las purinas como la azatioprina y reduce de forma potente la secreción de insulina por un mecanismo de bloqueo también de los canales de calcio.

El desarrollo de nuevos inmunosupresores se ha convertido en el factor determinante que ha permitido incrementar la tasa de insulin independencia tras el trasplante.

El sirolimus, cuya función depende de la unión a receptores intracitoplasmáticos formando un complejo que impide la proliferación de células T dependiente de IL-2 (inhibe las señales de proliferación de células T por IL-2 y otras citokinas y factores de crecimiento) no modifica la secreción de insulina por las células beta y por lo tanto carece de efecto diabetógeno.

El daclizumab, un anticuerpo monoclonal frente a la cadena alfa (CD 25) del receptor de la IL-2, no ha demostrado efectos deletéreos sobre la secreción de insulina ${ }^{55,56}$.

\section{Resultados del modelo clínico de trasplante de islotes en el humano}

Según datos recogidos en el Registro Internacional de Trasplante de Islotes (Universidad de Giessen, Alemania) entre los años 1983 y 1999 se realizaron un total de 493 alotrasplantes de islotes, 237 de los cuales lo fueron en la década 1990-1999 (Fig. 4). La supervivencia del receptor al año fue del 96\% mientras la supervivencia del injerto, definida como la determinación

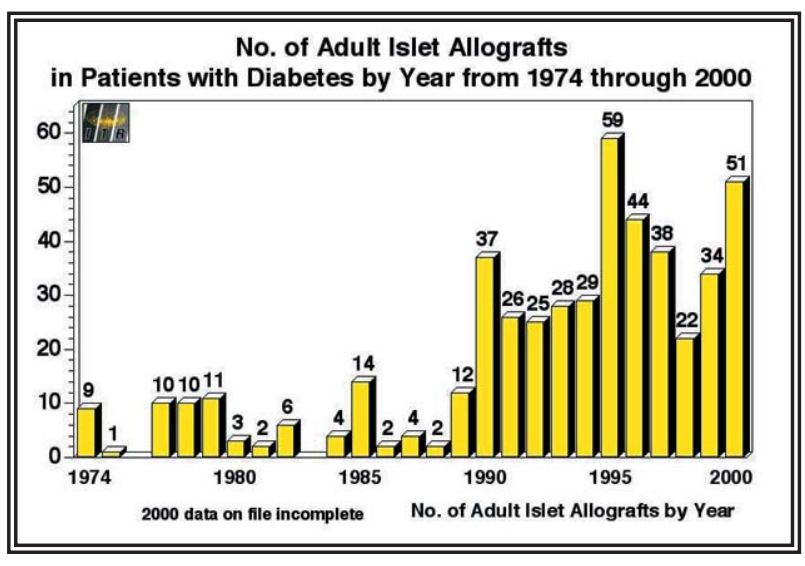

FIGURA 4. Número de Trasplantes Alogénicos de Islotes de Páncreas entre los años 1974-2000 (previo al Protocolo de Edmonton). Tomado de "International Islet Transplant Registry. ITR" con base en el Tercer Departamento Médico del Centro Médico Universitario de Giessen. Alemania. 2001.

de niveles de péptido $\mathrm{C}>0,5 \mathrm{ng} / \mathrm{ml}$ fue del $41 \%$ y la independencia de insulina del $11 \% 57$ (Fig. 5).

En junio del año 2000 fueron comunicados por Shapiro et al. los resultados obtenidos por un nuevo protocolo de trasplante clínico. Se seleccionaron pacientes con DM tipo 1 de más de 5 años de evolución con niveles indetectables de péptido-C y cuya característica fundamental era su labilidad con persistencia de niveles de glucosa no controlados a pesar de un estricto programa de tratamiento insulínico que conllevaba múltiples y severos episodios de hipoglucemia, así como episodios de cetoacidosis diabética.

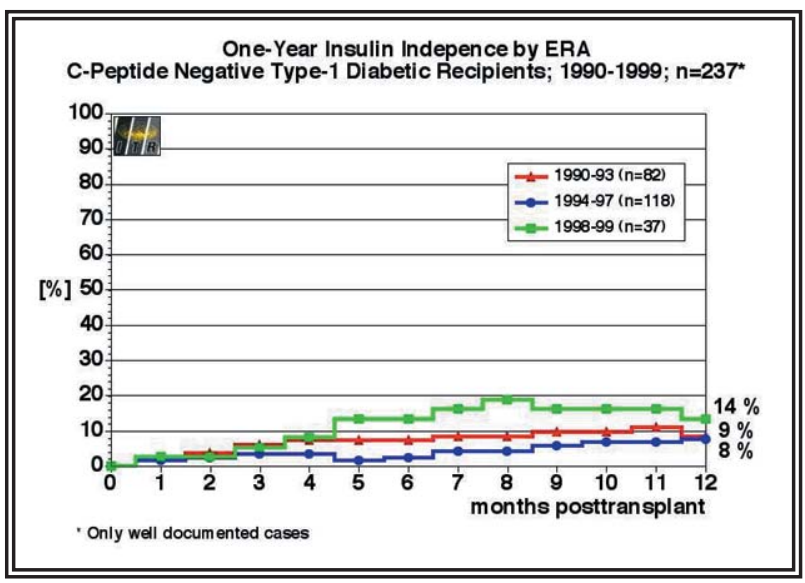

FIGURA 5. Independencia de Insulina al año postrasplante en pacientes diabéticos tipo 1 (péptido $C$ negativo) En la década 1990-1999). Tomado de "International Islet Transplant Registry. ITR" con base en el Tercer Departamento Médico del Centro Médico Universitario de Giessen. Alemania. 2001. 
El TI se llevó a cabo como procedimiento aislado, no asociado a TR, iniciándose el protocolo de inmunosupresión inmediatamente antes del TI con Sirolimus, Tacrolimus a dosis bajas y Daclizumab. Dicho protocolo, a diferencia de los previamente utilizados, evitaba el empleo en todo momento de glucocorticoides con reconocida capacidad diabetogénica.

Los páncreas se obtuvieron de donante cadáver. El procesamiento de la glándula comienza con su distensión canalicular con la enzima Liberasa y se sigue de la disrupción mecánica y digestión automatizada en cámara. El aislamiento de islotes se completa con la purificación automatizada en un separador celular COBE 2991 utilizando un gradiente continuo de FicollDitriazoato. El procedimiento evita el uso de derivados xenoproteicos como suplementos de las soluciones de lavado o medios de cultivo para disminuir el riesgo de estimular la respuesta inmune. El producto del aislamiento se trasplantaba en fresco. Las preparaciones se consideraron adecuadas para el trasplante cuando contenían $>4.000 \mathrm{IE} / \mathrm{Kg}$ peso del receptor y un volumen $<10 \mathrm{ml}$ y se trasplantaron mediante infusión portal trans-hepática percutánea de una suspensión de islotes en una solución constituida por medio 199 y albúmina humana con heparina mientras se efectúan el control de la presión intraportal. Al finalizar la infusión y para evitar el sangrado del trayecto de punción se embolizó con partículas hemostáticas.

El tratamiento insulinico se suspendia inmediatamente tras el trasplante y sólo se reiniciaba si el paciente presentaba glucemias $>200 \mathrm{mg} / \mathrm{dl}$ en cuyo caso se llevaba a cabo un retrasplante.

El protocolo descrito y sus resultados fueron inicialmente comunicados en 7 pacientes. Con un seguimiento medio de 11,9 meses (4,4-14,9 meses) el $100 \%$ de los pacientes se mantenía independiente del uso exógenos de insulina. Para ello, 6 de los 7 pacientes requirieron una segunda infusión de islotes y el paciente restante requirió hasta una tercera infusión. El número total medio de islotes trasplantados fue de 11.547 $\mathrm{IE} / \mathrm{Kg}$ (DE 1604 IE/Kg).

La estrategia inmunosupresora utilizada, que representa la modificación fundamental introducida responsable del éxito del protocolo, previene la activación de la cascada inmune inhibiendo la activación de células $\mathrm{T}$ (Tacrolimus), la producción de interleukina 2 (IL-2) y otras citoquinas (Sirolimus) y la unión de IL-2 a su ligando (Daclizumab) y por lo tanto inhibiendo la expansión clonal de los linfocitos.

En enero de $2002^{58}, 17$ pacientes habian sido receptores de un TI bajo el conocido como Protocolo de Edmonton, con un total de 38 procedimientos (13 pacientes requirieron 2 procedimientos y 4 precisaron 3 infusiones secuenciales) y un número medio de islotes equivalentes de 12.330 IE/Kg (DE $581 \mathrm{IE} / \mathrm{Kg}$ ). El tiempo medio de seguimiento fue de 20,4 meses (3,2-34,2). De los 17 pacientes, 11 permanecian insulin-independientes con una HgbA1c media de 5,8 \% (DE $0,13 \%$ ) para lo cual 2 pacientes requirieron el uso de hipoglucemientes orales. Cuando se aplican criterios estrictos en el test de estimulación oral de la glucosa sólo 2 pacientes tienen una tolerancia normal a la glucosa. De los 6 pacientes restantes que precisaron de nuevo tratamiento insulínico, 3, no tenían péptido-C detectable y 2 de ellos tuvieron seroconversión para anti GAD y anti ICA lo que expresa recurrencia de la enfermedad autoinmune. Asímismo uno de los pacientes en tratamiento con insulina pero con péptidoC detectable (3) ha verificado un incremento de anticuerpos ICA y GAD.

A pesar de lo expuesto, ningún paciente volvió a presentar episodios de hipoglucemia o un control glucémico lábil.

Los resultados obtenidos por Shapiro et al. fueron posteriormente reproducidos por otros grupos integrados en un ensayo multicéntrico bajo el patrocinio de la Inmuno Tolerance Network ${ }^{59}$.

Markmann et al. publican en diciembre de 2003 los resultados en el TI de 9 pacientes en el periodo comprendido entre febrero de 2000 y diciembre de 2002. Siete pacientes lograron la independencia de insulina, de los cuales 5 sólo requirieron un procedimiento, mientras los 2 restantes precisaron 2 infusiones. Sin embargo, de los 5 pacientes sometidos a un procedimiento único, 2 recibieron la infusión de islotes procedentes de 2 donantes. Tras un seguimiento mínimo de 1 año, 6 de los 7 receptores mantuvieron la insulin-independencia. 
En mayo de 2005 el Grupo de Edmonton publica la revisión de su resultados. Se habían tratado 70 receptores de islotes aislados ${ }^{60}$. Los estudios de supervivencia demostraban la pérdida progresiva de insulin-independencia con sólo el 50\% de los receptores independientes de insulina a los 3 años. Sin embargo, el 83\% de los pacientes continuaban mostrando detección de péptido-C a los 5 años.

A nivel mundial, más de 471 pacientes con DM tipo 1 han recibido un TI en 43 instituciones distintas desde el año 2000. A pesar de excelentes resultados a un año post-TI, a largo plazo la función del injerto declina significativamente con menos del $10 \%$ de los receptores independientes de insulina a los 5 años ${ }^{61-63}$.

Aunque la independencia de insulina se ha considerado el objetivo terapéutico primordial tras el TI, ésta debería lograrse simultáneamente a un adecuado control metabólico. La función del islote puede encontrase severamente alterada aún en condiciones de insulin independencia.

Los estudios llevados a cabo en receptores de auto TI ponen de manifiesto la posibilidad, tras el implante de una masa suficiente de islotes, el lograr un estado persistente de normoglucemia con una respuesta de insulina a los secretagogos glucosa y arginina característicamente bifásica, es decir, cualitativamente normal aunque con frecuencia cuantitativamente reducida. La reserva insulínica se encuentra también reducida, lo que se traduce en un riesgo de hiperglucemia en situaciones de estrés fisiológico. Sin embargo, la función secretora del alotrasplante de islotes parece significativamente alterada. La infusión portal de islotes en el hígado es una situación claramente desfavorable para la función endocrina de un islote denervado y desvascularizado, dado que, en primer lugar, la modulación autonómica de la secreción de insulina es fundamental para la homeostasis de la glucosa y en segundo lugar, la sangre venosa portal contiene niveles elevados de metabolitos intestinales, glucosa y drogras inmunosupresoras ${ }^{64}$.

La respuesta fisiológica al incremento de glucosa circulante es la secreción de insulina que alcanza el hígado por vía portal inhibiendo la producción de glucosa por el mismo. Los pacientes receptores de un alotrasplante muestran una primera fase de secreción de insulina defectuosa, así como una reducción de la segunda fase de secreción aguda de insulina que es primordial en la inhibición de la producción hepática de glucosa; el resultado es la hiperglucemia postpandrial detectada en los pacientes receptores de alotrasplantes funcionantes.

Los estudios de la homeostasis de la glucosa llevados a cabo por el grupo de Edmonton en pacientes con insulin independencia prolongada ponen de manifiesto en los test de tolerancia a la glucosa, respuestas de secreción de insulina significativamente inferiores a las de individuos controles no diabéticos.

Concomitantemente a una reproducción defectuosa del patrón de secreción de insulina se objetiva la ausencia de restablecimiento de la respuesta fisiológica a la hipoglucemia, conocida como contrarregulación de la glucosa. El defecto de la secreción de glucagón en respuesta a una hipoglucemia aguda o sostenida no es el resultado de la destrucción de células $\alpha$ en el islote, sino de la utilización del hígado como lugar receptor del implante pues la secreción de glucagón, sin embargo, es preservada en el contexto del TI peritoneal. El defecto de secreción de glucagón es específico del estímulo hipoglucémico pues se mantiene en respuesta al aminoácido arginina. El mecanismo propuesta para la inhibición específica del glucagón es la producción intrínseca de glucosa por los hepatocitos que constituyen tras el TI el microambiente insular. La producción de glucosa hepática que ocurre normalmente durante una situación de hipoglucemia (gluconeogénesis/glucogenolisis) sistémica es suficiente para inhibir la producción de glucagón en las células $\alpha$ del islote.

Finalmente, no se ha demostrado tras el TI la modificación de la alteración conocida de otros componentes de la respuesta contrarreguladora: la secreción de adrenalina y noradrenalina, la secreción de cortisol y hormona de crecimiento. La ausencia de recuperación de la secreción de adrenalina puede ser el resultado de la neuropatía autonómica instaurada en el paciente diabético de larga evolución. 


\section{MODELO EXPERIMENTAL DE AISLAMIENTO DE ISLOTES}

Sería deseable en el mismo momento del TR asociar un trasplante de tejido pancreático en el tracto genitourinario o en su proximidad, que permita la resolución del trastorno metabólico sin incrementar de modo significativo la morbimortalidad del TR.

Las consideraciones expuestas llevaron a considerar deseable, en el mismo momento del TR, asociar un trasplante de tejido pancreático en el tracto genitourinario o en su proximidad, que permita la resolución del trastorno metabólico sin incrementar de modo significativo la morbimortalidad del TR.

Se desarrolló una hipótesis de trabajo experimental en modelo animal cuyo objetivo fuera evaluar la viabilidad de una técnica de aislamiento de islotes y a analizar comparativamente la idoneidad de distintos sitios de implantación en el tracto genito-urinario que incluyera la subcápsula renal del injerto, la submucosa vesical y el parénquima testicular.

\section{MATERIAL Y MÉTODOS}

El trabajo experimental se llevó a cabo en 2 fases diferenciadas. El objetivo de la Primera Fase fue el desarrollo de la técnica de aislamiento de islotes para lo cual se desarrolló un modelo de animal pequeño en rata. La técnica de digestión pancreática perfeccionada en la fase previa permitió el aislamiento y TI en un modelo experimental de autoTR en cerdo que constituye la Segunda Fase del trabajo experimental.

\section{MODELO EXPERIMENTAL EN CERDO}

Una vez desarrollada la metodología de digestión pancreática manual, ésta se trasfirió a un modelo experimental en cerdo. La hipótesis de trabajo exigía la asociación del TI a un modelo experimental de autoTR.

\section{Animales de experimentación. Preparación preoperatoria}

Los animales de estudio fueron 20 cerdos macho adultos de tipo hébrido comercial (mezcla genética de los tipos Landrace, large White y Pietrain) con una media de edad de 5,5 (SD 1,1) meses y una mediana de peso de $53(30,102) \mathrm{Kg}$.
El cerdo es un animal ampliamente utilizado en el ámbito del trasplante experimental ya que posee una anatomía y fisiología muy similares al humano. Se trata además, de un animal de fácil obtención, crecimiento rápido y reproducción numerosa. Sin embargo, es, asímismo, un animal de naturaleza lábil y sensible a las situaciones de estrés por lo que su manejo debe ser cuidadoso para evitar la muerte del animal durante su preparación para la intervención. Todos los animales, procedentes de la misma granja especializada, se mantuvieron en condiciones estándar de estabulación donde se les proporcionaba agua y comida en forma de pienso. Los animales eran sometidos a un periodo de ayunas de $24 \mathrm{~h}$ previo a la cirugía pero con acceso libre al agua. La premedicación del animal se lleva a cabo con la administración intramuscular de ketamina a dosis de $10 \mathrm{mg} / \mathrm{kg}$. Trasladado al prequirórfano el animal se pesa y se canaliza la vena del pabellón auricular y se traslada a la mesa de quirófano donde se realiza la inducción anestésica con Sulfato de atropina $(0,7 \mathrm{mg} / \mathrm{kg})$ y Tiopental sódico intravenoso $(15 \mathrm{mg} / \mathrm{kg})$ que se sigue de la intubación orotraqueal y ventilación controlada del animal. Se realiza profilaxis antibiótica con Cefazolina/1 g iv) y Metronidazol (500 mg iv).

\section{Modelo quirúrgico. Extracción renal y pancreática. Técnica anestésica}

El mantenimiento anestésico se realiza con Isoflurano al 0,7\% y el bloqueo neuromuscular con Bromuro de pancuronio (2 $\mathrm{mg} / \mathrm{kg} / \mathrm{h})$. La analgesia intraoperatoria se realiza con Fentanilo a dosis de $50 \mu \mathrm{gr} / \mathrm{h}$. La monitorización hemodinámica de los animales se lleva a cabo mediante la canulación del paquete vascular femoral en el que arteria vena son cateterizadas con un catéter de doble luza (CVP Catheter 2 lumen Abbott ${ }^{\mathrm{R}}$ ) lo que permite la monitorización continua de la presión arterial (PA) y de la presión venosa central (PVC).

\section{Técnica quirúrgica de extracción renal}

El animal se coloca en decúbito lateral derecho en posición de lumbotomía izquierda y se prepara el campo quirúrgico correspondiente al acceso de lumbotomía subcostal. Tras acceder 
a la fosa lumbar se penetra en el espacio retroperitoneal y se procede a la disección del espacio perirrenal y a la identificación y disección de los elementos del pedículo renal, arteria y vena y el uréter. La colocación en la arteria renal principal de una sonda de ultrasonidos (T10S Samall animal blood flowmeter. Probe 4R1182. Transonic Systems Inc. New York. USA) permite la monitorización del flujo arterial renal. A continuación se canula el uréter previamente seccionada con una sonda de alimentación $\mathrm{K}-30$ lo que permite la monitorización de la diuresis y la determinación del aclaramiento renal. Finalizado lo cual se realiza la nefrectomía izquierda.

\section{Técnica quirúrgica de pancreatectomia segmentaria}

El páncreas del cerdo es un órgano retroperitoneal cuyos $3-4 \mathrm{~cm}$ distales correspondientes a la cola pancreática están recubiertos por una cápsula fibrosa y se disponen sobre el hilio esplénico mientras el cuerpo de la glándula envuelve la vena porta.

Una vez efectuada la nefrectomía izquierda, el páncreas del animal se identifica inmediatamente anterior a la posición que ocupaba el polo superior del riñón izquierdo. La cápsula fibrosa que envuelve el segmento caudal de la glándula facilita su disección conservando íntegra dicha cápsula. Una vez alcanzado el eje portal se realiza la sección mecánica automática del órgano con un dispositivo Roticulator (Disposable Stapler Autosuture) (Fig. 6).

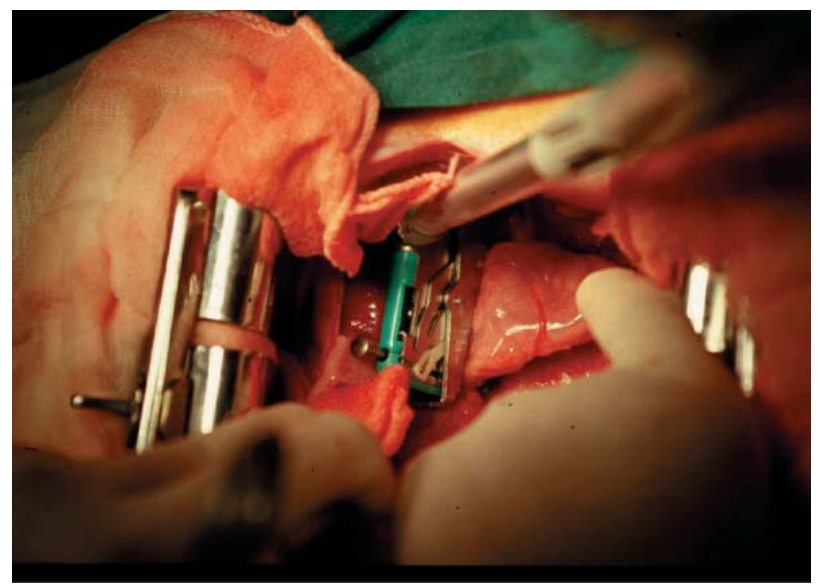

FIGURA 6. Sección mecánica del segmento distal del páncreas.

\section{Preservación del injerto pancreático. Preservación del injerto renal}

Una vez finalizada la nefrectomía izquierda, el riñón es inmediatamente perfundio con $250 \mathrm{ml}$ de solución de Wisconsin a $4^{\circ} \mathrm{C}$ e introducido en un contenedor, asimismo, con solución de Wisconsin y sumergido en hielo en nevera para su preservación por enfriamiento de superficie.

El injerto pancreático obtenido es sumergido en solución de Wisconsin a $4{ }^{\circ} \mathrm{C}$ y trasladado al Laboratorio de Inmunopatología para iniciar su procesamiento.

\section{Curso postoperatorio}

La intervención quirúrgica finaliza con el cierre de la lumbotomía izquierda y la creación de un bolsillo subcutáneo para la introducción y conservación del acceso vascular femoral. Una vez recuperado el tono neuromuscular el animal es extubado y trasportado a las dependencias del animalario.

\section{Procesamiento pancreático}

El procesamiento del segmento pancreático se lleva a cabo en condiciones de esterilidad bajo cámara de flujo laminar en el Laboratorio de Inmunopatología a donde ha sido trasladado inmediatamente tras su extracción. La media de tiempo de isquemia fría fue de 13,76 (SD 6,03) min.

El procedimiento comienza con el pesado del segmento pancreático en una balanza de precisión, tras lo cual se dispone en una cápsula de acero inoxidable. Se canula el conducto pancreático con un Abbocath-t $24 \mathrm{G}$ y se perfunde con un volumen de solución de colagenasa de concentración 1,5 mg/ml, igual al peso del segmento pancreático multiplicado por 3 hasta obtener la distensión de la glándula (Fig. 7). A continuación se procede a la disección de la cápsula y grasa peripancreáticas y a la dispersión mecánica del páncreas en solución de colagenasa. Se inicia la agitación en baño termostatizado a $38^{\circ} \mathrm{C}$ durante 10-12 min. Finalizada la agitación se distribuye el producto de digestión en tubos de Falcon de $50 \mathrm{ml}$ para su centrifugación a $400 \mathrm{G}$ a $4^{\circ} \mathrm{C}$ durante $2 \mathrm{~min}$, proceso que se repite en iguales condiciones una vez retirado el sobrenadante y resuspendido el pellet en solución de HANKS. Tras la segunda centrifugación se resuspende el 


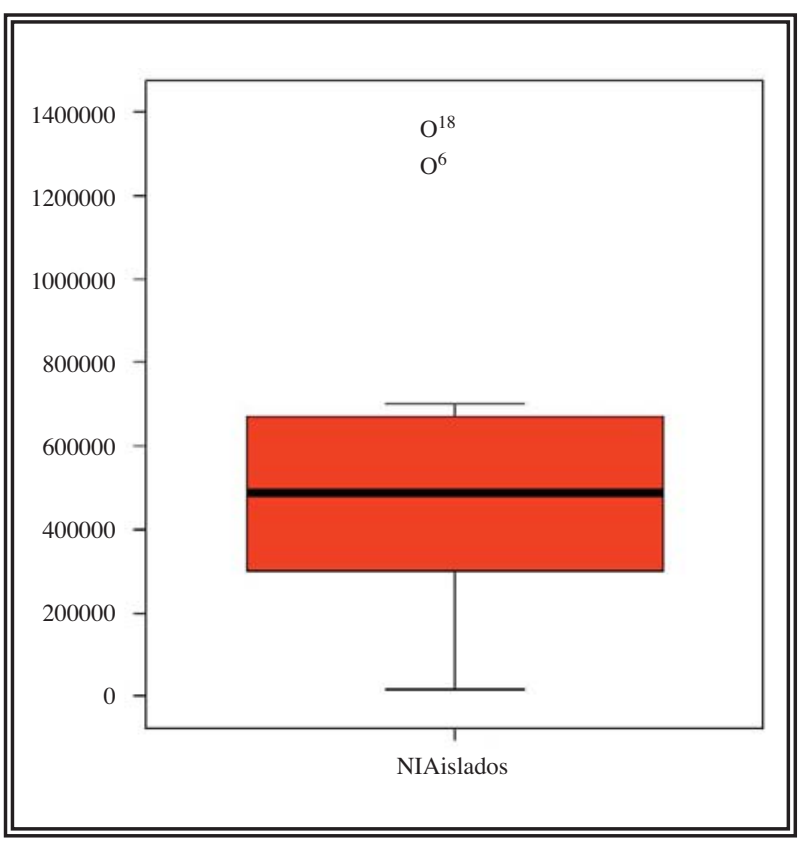

FIGURA 7. Resultados. Número de Islotes Pancreáticos.

pellet resultante en medio de cultivo RPMI 1640 y se dispone en placas de Petri para su cultivo en estufa a $37^{\circ} \mathrm{C}$ y $5 \% \mathrm{CO} 2$ donde permanecen hasta su implante. El recuento de islotes requiere la separación de un alicuota de $100 \mu 1$ del producto de digestión que se incuba con $10 \mu 1$ de DTZ durante $5 \mathrm{~min}$ para la tinción selectiva de los islotes viables. En una placa de Petri de $25 \mathrm{~mm}$ se visualizan bajo microscopio de luz invertida con visor graduado y se cuentan distribuidos por tamaño. El producto obtenido es , pues, el resultado de la digestión enzimática y dispersión mecánica pancreática.

\section{Trasplante de islotes asociado a trasplante renal}

Trascurridas 24 horas, el animal es trasladado de nuevo al área quirúrgica.

\section{Técnica anestésica}

El procedimiento anestésico sigue el protocolo previamente descrito, comenzando con la premedicación del animal con Ketamina $(10 \mathrm{mg} / \mathrm{kg})$. La conservación del acceso vascular femoral permite su empleo para la inducción anestésica con Tiopental sódico $(15 \mathrm{mg} / \mathrm{kg})$ y Solfato de atropina $(0,7 \mathrm{mg} / \mathrm{kg})$ que se sigue de la intubación de la vía aérea del animal y su ventilación mecánica.

\section{Técnica de nefrectomia derecha. Animal anéfrico}

Con el animal en posición de decúbito lateral izquierdo, se prepara el campo quirúrgico para acceso de lumbotomía subcostal derecha. Se alcanza el espacio retroperitoneal a nivel de la fosa lumbar procediéndose a la disección del espacio perirrenal y al aislamiento del pedículo renal, momento en el que se determina el flujo arteria renal en el animal monorreno con sonda de ultrasonidos. Concluida la determinación se realizará la nefrectomía derecha tras el clampaje de la a. Renal a nivel del ostium aórtico, el clampaje de la v. Renal en el ostium de la cava y la sección ureteral.

\section{Técnica de auto-trasplante renal ortotópico}

El injerto renal izquierdo, que ha permanecido preservado mediante inmersión en solución de Wisconsin y enfriamiento de superficie se saca de hielo. El autoTR ortotópico se inicia con la anastomosis venosa termino-terminal a v. Renal con sutura continúa interrumpida de Prolene ${ }^{R}$ 5-0, seguida pro la anastomosis arterial terminoterminal a a. Renal con sutura continua interrumpida de Prolene ${ }^{R} 5-0$. Una vez finalizada la anstomosis arterial se coloca la sonda de ultrasonidos distal a la línea de sutura. El desclampaje sucesivo venoso y arterial permite la reperfusión del injerto mientras la sonda monitoriza el flujo arterial y su modificación en el tiempo. La cateterización del uréter del injerto permite la monitorización de la diuresis y junto con el flujo arterial la determinación del aclaramiento renal. El auto-TR finaliza con la anastomosis urétero-ureteral termino-terminal con puntos sueltos de Vycril $^{\mathrm{R}}$ 4-0.

\section{Técnica de autotrasplante de islotes pancreáticos}

Los islotes pancreáticos (IP) que han permanecido en cultivo, previa verificación de su viabilidad mediante tinción selectiva con DTZ, son distribuidos en 4 volúmenes homogéneos y dispuestos en 4 jeringas de $1 \mathrm{cc}$.

\section{TI en la subcapsula renal del injerto}

A nivel del injerto renal, la creación de un túnel subcapsular mediante un catéter balón (Biliary balloon probe. $5 \mathrm{Fr}$. Dispomédica. Hamburg. 
Germany) permite la inyección de los islotes y el sellado de la cápsula renal con cola de fibrina $\left(\right.$ Tissucol $\left.{ }^{R}\right)$. A continuación se cierra el acceso de lumbotomía.

\section{TI en la submucosa vesical}

Con el animal en decúbito supino y a través de una laparotomía media se accede a la vejiga localizada en posición intraperitoneal. A nivel de la cúpula vesical la incisión de la capa muscular permite la disección del espacio submucoso y la inyección de un segundo alicuota de islotes.

\section{TI en el testículo}

La luxación intra-abdominal del testículo permitirá la inyección intra-parenquimatosa y vía deferencial de islotes y su permanencia intraabdominal.

\section{Curso postoperatorio}

El procedimiento finaliza con el cierre del acceso de laparotomía media, la reanimación del animal y su traslado a las dependencias de estabulación del animalario.

\section{Sacrificio}

El $7^{\circ}$ día postoperatorio el animal se traslada a quirófano y tras la inducción anestésica según protocolo, el animal se coloca en posición de lumbotomía derecha y a través de la incisión previa se accede al espacio retroperitoneal. Se efectúa la liberación extracapsular del injerto y el control del pedículo vascular que permita la determinación del flujo arterial con sonda de ultrasonidos, tras lo cual se realiza nefrectomía del injerto. A través de la laparotomía media se verificarán la cistectomía parcial del segmento donde se realizó la inyección submucosa de islotes y finalmente la orquiectomía.

Las piezas de nefrectomía, cistectomía parcial y orquiectomía son incluidas en formol para su estudio anatomopatológico.

El sacrificio del animal se lleva a cabo mediante inyección letal de ClK.

\section{RESULTADOS}

El modelo se llevó a cabo en un total de 20 animales. Todos ellos procedentes de la misma granja de estabulación y pertenecientes a la raza híbrido comercial (mezcla genética de los tipos Landrace, large White y Pietrain). La edad media de los animales fue de 5,5 (SD 1,1) meses y una mediana de peso de $53(30,102) \mathrm{Kg}$.

En 4 de los animales (4/20) la extracción pancreática no se realizó. El animal 1, que fue el único en el que el acceso pancreático se verificó por vía de una laparotomía media, sufrió una lesión quirúrgica del eje venoso portal que ocasionó su muerte. El animal 5 murió a consecuencia de un cuadro de hipertermia maligna durante el mantenimiento anestésico. El animal 13 presentó una lesión vascular arterial del riñón izquierdo destinado al autotrasplante durante la extracción que le inhabilitó para el modelo. Finalmente el animal 19 sufrió una lesión del segmento distal del páncreas.

Los segmentos pancreáticos obtenidos quirúrgicamente estuvieron perfundidos hasta su sección y por lo tanto no sufrieron isquemia caliente. El traslado del segmento pancreático al Laboratorio de Inmunopatología para su procesamiento se realizaba de forma inmediata tras su obtención por lo que el tiempo medio de isquemia fría fue de 13,76 (SD $6,037)$ min. El peso medio de la glándula fue de 25 , 47 (SD 11,19) g (Tablas 1, 2 y 3).

Tabla 1. Características de los animales

\begin{tabular}{cccccc}
\hline & Animal & $\begin{array}{c}\text { Peso } \\
\text { del animal } \\
\text { (Kg) }\end{array}$ & $\begin{array}{c}\text { Edad del } \\
\text { animal } \\
\text { (meses) }\end{array}$ & $\begin{array}{c}\text { Tiempo de } \\
\text { isquemia } \\
\text { fria (min) }\end{array}$ & $\begin{array}{c}\text { Peso del } \\
\text { páncreas } \\
\text { (g) }\end{array}$ \\
\hline 1 & 1 & 36 & 3 & - & - \\
2 & 2 & 42 & 4 & 8 & 19,0 \\
3 & 3 & 76 & 5 & 12 & 32,0 \\
4 & 4 & 95 & 6 & 15 & 46,0 \\
5 & 5 & 55 & 5 & - & - \\
6 & 6 & 31 & 5 & 30 & 15,0 \\
7 & 7 & 63 & 5 & 12 & 38,0 \\
8 & 8 & 34 & 3 & 10 & 13,0 \\
9 & 9 & 37 & 4 & 25 & 17,0 \\
10 & 10 & 42 & 4 & 8 & 16,5 \\
11 & 11 & 51 & 4 & 15 & 13,5 \\
12 & 12 & 41 & 4 & 10 & 15,5 \\
13 & 13 & 84 & 6 & 10 & 36,0 \\
14 & 14 & 30 & 3 & 15 & 16,0 \\
15 & 15 & 31 & 3 & 12 & - \\
16 & 16 & 59 & 5 & 20 & 24,0 \\
17 & 17 & 102 & 6 & 10 & 39,0 \\
18 & 18 & 98 & 6 & 12 & 38,0 \\
19 & 19 & 64 & 5 & - & - \\
20 & 20 & 91 & 6 & 10 & 29,0 \\
Total N & 20 & 20 & 20 & 17 & 16 \\
\hline & & & & & \\
\hline
\end{tabular}

Limitados los primeros 100 casos 
Tabla 2. Resultados. Estadísticos descriptivos

\begin{tabular}{lccccc}
\hline & N & Mínimo & Máximo & Media & Desviación estándar \\
\hline Peso del animal (Kg) & 20 & 30 & 102 & 58,10 & 24,770 \\
Edad animal (meses) corregida & 20 & 3,50 & 6,50 & 5,1000 & 1,09545 \\
Peso del páncreas (gr) & 16 & 13,0 & 46,0 & 25,469 & 11,1900 \\
Tiempo de isquemia fría (min) & 17 & 8 & 30 & 13,76 & 6,037 \\
Valid N (listwise) & 16 & & & & \\
\hline
\end{tabular}

Tabla 3. Resultados. Características de los animales.

\begin{tabular}{lcccc}
\hline & $\begin{array}{c}\text { Peso del } \\
\text { animal } \\
\text { (Kg) }\end{array}$ & $\begin{array}{c}\text { Edad del } \\
\text { animal } \\
\text { (meses) }\end{array}$ & $\begin{array}{c}\text { Peso del } \\
\text { páncreas } \\
\text { (g) }\end{array}$ & $\begin{array}{c}\text { Tiempo de } \\
\text { isquemia fria } \\
\text { (min) }\end{array}$ \\
\hline N Validos & 20 & 20 & 16 & 17 \\
Missing & 0 & 0 & 4 & 3 \\
Media & 58,10 & 5,1000 & 25,469 & 13,76 \\
Error estándar de la media & 5,539 & 0,24495 & 2,7975 & 1,464 \\
Mediana & 53,00 & 5,5000 & 21,500 & 12,00 \\
Desviación estándar & 24,770 & 1,09545 & 11,1900 & 6,037 \\
Rango & 72 & 3,00 & 33,0 & 22 \\
Mínimo & 30 & 3,50 & 13,0 & 8 \\
Máximo & 102 & 6,50 & 46,0 & 30 \\
\hline
\end{tabular}

humanos con tiempos de isquemia fría inferiores a 6-8 horas. En nuestro modelo el tiempo de isquemia fría fue siempre inferior a 1 hora y la preservación se realizó por inmersión simple en Wisconsin a $4{ }^{\circ} \mathrm{C}$. Se ha demostrado la eficacia de la distensión pre-enfriamiento del conducto pancreático con solución de Wisconsin o de colagenasa en Wisconsin para preservar la integridad del conducto y permitir la completa distensión de la glándula. La solución de colagenasa permanece inactiva
Cuatro segmentos pancreáticos procesados (animales 8, 11, 14 y 17) tuvieron una digestión fallida, no pudiéndose identificar islotes viables tras la tinción con DTZ del producto de digestión enzimática.

Se obtuvieron, por lo tanto, islotes tras el procedimiento de digestión en 12 animales La Tabla muestra los resultados de aislamiento expresados como Número de Islotes Aislados (Tablas 4 y 5) (Fig. 7).

El estudio anatomopatológico tras el sacrificio del animal permitió identificar la presencia de islotes en 2 ejemplares $(2 / 12,16 \%)$. En el primero de ellos la localización viable correspondió al testículo tras inyección intracanalicular (Fig. 8), mientras en el segundo se identificaron en la submucosa vesical.

\section{DISCUSIÓN}

El primer factor limitante en el proceso de aislamiento es la preservación del órgano para lo cual la solución de Wisconsin se ha demostrado la más idónea tanto en modelos animales como
Tabla 4. Resultados. Digestión de islotes

\begin{tabular}{|c|c|c|c|}
\hline & Animal & $\begin{array}{c}\text { Peso del } \\
\text { páncreas (g) }\end{array}$ & NIAislados \\
\hline 1 & 1 & - & - \\
\hline 2 & 2 & 19,0 & 450000 \\
\hline 3 & 3 & 32,0 & 16000 \\
\hline 4 & 4 & 46,0 & 520000 \\
\hline 5 & 5 & - & - \\
\hline 6 & 6 & 15,0 & 1260000 \\
\hline 7 & 7 & 38,0 & 170000 \\
\hline 8 & 8 & 13,0 & Digestión Fallida \\
\hline 9 & 9 & 17,0 & 300000 \\
\hline 10 & 10 & 16,5 & 700000 \\
\hline 11 & 11 & 13,5 & Digestión Fallida \\
\hline 12 & 12 & 15,5 & 300000 \\
\hline 13 & 13 & 36,0 & - \\
\hline 14 & 14 & 16,0 & Digestión Fallida \\
\hline 15 & 15 & - & 520000 \\
\hline 16 & 16 & 24,0 & 300000 \\
\hline 17 & 17 & 39,0 & Digestión Fallida \\
\hline 18 & 18 & 38,0 & 1350000 \\
\hline 19 & 19 & - & - \\
\hline 20 & 20 & 29,0 & 640000 \\
\hline Total N & 20 & 16 & 12 \\
\hline
\end{tabular}


Tabla 5. Resultados. Número de islotes aislados

\begin{tabular}{llcc}
\hline & & $\begin{array}{c}\text { Peso del } \\
\text { páncreas (g) }\end{array}$ & NIAislados \\
\hline $\mathrm{N}$ & Válidos & 16 & 12 \\
& Missing & 4 & 8 \\
Mediana & & 21,500 & 485000,00 \\
Rango & & 33,0 & 1334000 \\
Mínimo & 13,0 & 16000 & \\
Máximo & & 46,0 & 1350000 \\
Percentiles & 25 & 15,625 & 300000,00 \\
& 50 & 21,500 & 485000,00 \\
& 75 & 37,500 & 685000,00 \\
\hline
\end{tabular}

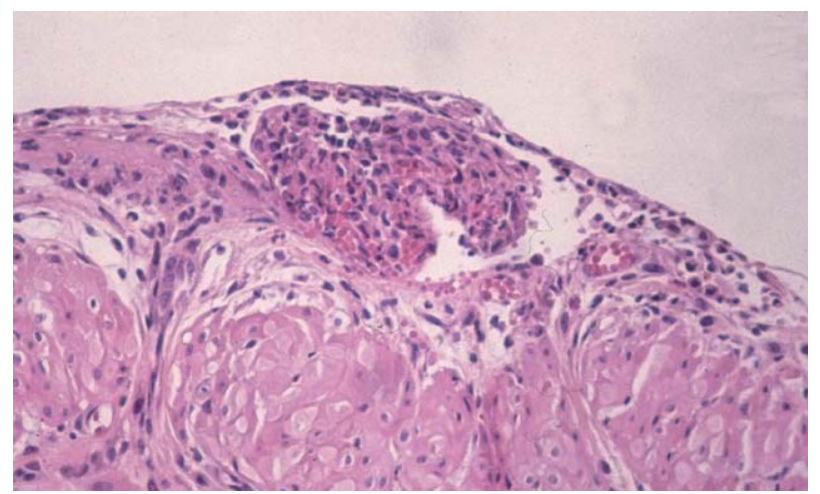

FIGURA 8. Imagen histopatológica. Tinción H-E. Islotes viables en el parénquima testicular.

durante el periodo de preservación a $4^{\circ}$. Una reciente modificación conocida como preservación en 2 capas utiliza el perfluorocloruro como un transportador de oxígeno al órgano sumergido en Wisconsin.

El método de disociación pancreática elegido determina su volumen final y pureza. El método de preparación varía desde la microdisección pancreática hasta la asociación de dispersión mecánica, digestión enzimática y purificación que consiguen la obtención de preparaciones progresivamente más puras, constituidas por tejido endocrino disociado del tejido acinar. Los procesos de purificación inicialmente desarrollados para disminuir la inmunogenicidad de la preparación continúan siendo motivo de controversia. La demostración de la capacidad inmunogénica intrínseca de los islotes cuestiona su necesidad.

Las técnicas de aislamiento no automatizadas requieren minimos recursos y los recuentos obtenidos pueden, en principio, ser tan adecuados como con los métodos automatizados, si bien menos reproducibles. La sencillez del método manual fue la razón de elección en nuestro modelo. Aunque la técnica básica reproduce la descrita por Lacy y Kostianowsky, ha sufrido modificaciones. El procesamiento y cultivo, generalmente aceptado a $37^{\circ}$ se ha visto modificado por la demostración de que el cultivo a temperaturas entre 22 y $24^{\circ}$ en primer lugar mejora la actividad de colagenosa y la tasa de aislamiento y en segundo lugar colabora al desarrollo de inmunotolerancia destruyendo las células presentadoras de antígeno acompañantes del islote y que estimulan la vía directa de la respuesta inmune ${ }^{65}$.

Los resultados de nuestro estudio confirman los hallazgos de la literatura. La técnica manual de procesamiento y digestión permite indudablemente la obtención de islotes, sin embargo el número de los mismos es ampliamente variable como resultado de la falta de reproductibilidad del procedimiento. La escasez de tejido conectivo en torno a los islotes en el páncreas del animal joven hace que los mismos resulten enormemente frágiles y con tendencia a la fragmentación, limitación que encontramos en nuestro modelo en el que se utilizaron animales con edades comprendidas entre 3 y 6 meses. La técnica clásica de evaluación de los resultados de la digestión que es el contaje de islotes equivalentes (definido islote equivalente como aquel mayor de 150 micras) resulta, en el caso del cerdo por tanto, inadecuada, motivo por el cual nuestros resultados se expresaron como número de islotes identificables mediante tinción obtenidos. Los métodos automatizados disminuyen el traumatismo sobre los islotes, consiguen resultados reproducibles y pueden ser utilizados para procesar grandes cantidades de tejido, motivos que nos condujeron a la construcción de una cámara automatizada según el diseño anterior de Ricordi66.

La relación donante-receptor determina la carga antigénica y por lo tanto la necesidad de purificación, la posibilidad de rechazo y la obligación de inmunosupresión.

La elección de un modelo de autotrasplante nos permitió eliminar los factores de confusión inmunológicos y la inmunosupresión así como la necesidad de purificación. 
El conocimiento de que el implante en un ambiente hiperglucémico ejerce un efecto deletéreo en la función y supervivencia del injerto justifica la realización de una pancreatectomía parcial en el modelo de autotrasplante en cerdo.

El pequeño volumen de la preparación obtenida por la combinación de microdisección pancreática y digestión enzimática hizo viable los diferentes lugares de implantación elegidos. Un determinante clave en la supervivencia a largo plazo del injerto, es la posibilidad de neovascularización que ofrece el lugar de implantación. Múltiples trabajos experimentales han demostrado la posibilidad de supervivencia del injerto a nivel hepático tras su infusión portal, esplénica y de la subcápsula renal así como a nivel testicular. En nuestro trabajo el espacio subcapsular renal no permitió la identificación de islotes tras su inyección lo que podría estar en relación con la desvascularización y denervación capsular del riñón obtenido para su trasplante. El ensayo del espacio submucoso de la vejiga que como lugar de implantación reuniría las características de accesibilidad y adecuada perfusión tisular permitió la identificación de islotes en el animal de experimentación. Así mismo, se identificaron islotes a nivel testicular por vía intracanalicular retrógrada. El testículo se ha propuesto como lugar inmunoprivilegiado que sustenta aloinjertos variados, aunque en el momento actual el mecanismo responsable y el papel último de la célula de Sertoli no se conocen.

\section{CONCLUSIONES}

1. La técnica de digestión enzimática manual permitió la obtención de islotes pancreáticos en un modelo en cerdo.

2. La escasa reproducibilidad de la técnica hace aconsejable la utilización de técnicas automatizadas.

3. La viabilidad de los islotes resultado de la digestión pancreática fue inicialmente demostrada por su tinción con el colorante vital DTZ tras su permanencia en cultivo.

4. El implante de los islotes obtenidos en el espacio subcapsular del injerto renal no permitió la supervivencia de los mismos como probable consecuencia de la desvascularización y denervación de la cápsula renal.
5. La supervivencia del implante testicular intracanalicular aporta una nueva vía de acceso que no requiere la punción directa del parénquima testicular.

6. Por primera vez, se demostró la viabilidad de la submucosa vesical como lugar de implante.

\section{REFERENCIAS}

1. Bennett Peter H. y Knowler William C. Definición, diagnóstico y clasificación de la diabetes mellitus y homeostasis de la glucose. En: Kahn C. R, Weir G.C., George L.K., King G.L.; Jacobson A.M., Moses A.C. and Smith R.J. directores. DiabetesMellitus. 14 ed. Boston: Lippincott Williams \& Wilkins; 2006. p. 331-339.

2. Warram J.H. y Krolewski A.S. Epidemiologia de la diabetes mellitus. En Kahn C. R, Weir G.C., George L.K., King G.L.; Jacobson A.M., Moses A.C. and Smith R.J. directores. Diabetes Mellitus. 14 ed. Boston: Lippincott Williams \& Wilkins; 2006. p.342-354.

3. Libman I, Songer T, LaPorte R. How many people in the U.S. have IDDM ?. Diabetes Care. 1993;16(5):841-842.

4. Harris MI, Hadden WC, Knowler WC, Bennett PH. Prevalence of Diabetes and Impaired glucose tolerance and plasma glucose levels in U.S. Population aged 20-74 yr. Diabetes. 1987;36(4):523-534.

5. Goday A, Serrano Rios M. Epidemiología de la diabetes mellitus en España. Revisión crítica y nuevas perspectivas. Medicina Clínica. 1994; 102(8):306-315

6. Nathan DM. Long-term complications of Diabetes Mellitus. N Engl J Med 1993; 328(23):1676-1685.

7. Friedman E.A. Advanced glycosylated end products and hyperglycemia in the pathogenesis of diabetic complications. Diabetes Care. 1999;22 (2):B65-B71.

8. Selby JV, FitzSimmons SC, Newman JM, Katz PP, Sepe S, Showstack J. The natural history and epidemiology of diabetic nephropathy. JAMA. 1990;263(14):1954-1960.

9. Marcantoni C, Ortalda V, Lupo A, Maschio G. Progression of renal failure in diabetc nephropathy. Nephrol Dial Transplant. 1998;13(Suppl 8):16-19.

10. Lenisa L, Castoldi R, Socci C, Motta F, Ferrari G, Spotti D, Et al. Cost-effective treatment for diabetic end-stage renal disease: dialysis, kidney, or kidney-pancreas transplantation?. Transplant Proc. 1995;27(6): 3108-3113.

11. European Dialysis and Transplant Association. European Rena Association. ERAEDTA Registry 2001 Annual Report. Academic Medical Center, Amsterdam. The Netherlands. 2003.

12. International Pancreas Transplant Registry at The University of Minnesota. USA from the 2003 Annual Report.

13. Marroquin CE, Edwards EB, Collins BH, Desai DM, Tuttle-Newhall JE Kuo PC. Half-life analysis of pancreas and kidney transplants. Transplantation. 2005;80(2):272-275.

14. Farney AC, Cho E, Schweitzer EJ, Dunkin B, Philosophe B, Colonna J, et al. Simultaneous cadever pancreas living-donor kidney transplantation: a new approach for the type 1 diabetic uremic patient. Ann Surg. 2000;232(5):696-703

15. Wideman L, Elahi D, Hanks J. Whole organ transplantation and glucose regulation. World J Surg. 2001;25(4):516-522.

16. Diem P, Redmon JB, Abid M, Moran A, Sutherland DE, Halter JB, et al. Glucagon, catecholamine and pancreatic polypeptide secretion in type I diabetic recipients of pancreas allografts. J Clin Invest. 1990;86(6): 2008-2013

17. Ricordi C. Islet Trasplantation: A brave new world. Diabetes. 2003;52(7):1595-1603.

18. Ricordi C, Finke EH, Dye ES, Socci C, Lacy PE. Automated isolation of mouse pancreatic islets. Transplantation. 1988; 46(3):455-457.

19. Ricordi C, Lacy E, Scharp DW. Automated islet isolation from human pancreas. Diabetes 1989;38(1):140-142.

20. Lakey J.R.T., Rajotte R.V., Warnock G.L. y Kneteman N.M. Pancreas procurement for islet isolation and pancreas storage prior to islet isolation. En: Camilo Ricordi director. Methods in Cell Transplantation. Austin, Texas. R.G. Landes Company; 1995. p 421-431. 
21. Ricordi C. y Rastellini C. Automated Method for pancreatic islet separation. En: Camilo Ricordi director. Methods in Cell Transplantation. Austin, Texas. R.G. Landes Company; 1995. p 433-454.

22. Burghen GA, Murrell LR. Factors influencing isolation of islets of Langerhans. Diabetes. 1989;38(Suppl 1):129-132.

23. Kenmochi T, Asano T, Jingu K, Iwashita C, Miyauchi H, Takahashi S, et al Development of a fully automated islet digestion system. Transplant Proc. 2000;32(2):341-343.

24. Latif ZA, Noel J, Alejandro R. A simple method of staining fresh and cultured islets. Transplantation. 1988;45(4): 827-830.

25. Gotoh M, Ohzato H, Porter J, Maki T, Monaco AP. Crucial role of pancreatic ductal collagenase injection for isolacion of pancreatic islets. Horm Metab Res Suppl. 1990;25:10-16.

26. Hesse UJ, Meyer GP, Weyer J, Schmitz-Rode M, Danis J, Tunggal B. In situ intraductal collagenase injection for preparation of islets of Langerhans in the pig. Transplant Proc. 1992;24(3):1007-1009.

27. Gill JF, Chambers LL, Baurley JL, Ellis BB, Cavanaugh TJ, Fetterhoff TJ, et al. Safety testing of liberase, a purified enzyme blend for human islet isolation. Transplant Proc. 1995;27(6):3276-3277.

28. Linetsky E,Bottino R, Lehmann R, Alejandro R, Inverardi L, Ricordi C. Improved human islet isolation using a new enzyme blend, Liberase. Diabetes. 1997;46(7):1120-1123.

29. Fiedor P, Sung RS, Goodman ER, Oluwole SF, Licinska I, Mazurek PA et al. Efficacy and safety of Dithizone in staining of islet cell transplants. Transplant Proc. 1995;27(6):2984.

30. Fiedor PS, Oluwole SF, Hardy MA. Localization of endocrine pancreatic islets. World J Surg. 1996;20(8): 1016-1022.

31. Gores PF, Sutherland DE. Pancreatic islet transplantation: Is purification necessary ?. Am J Surg. 1993;166(5):538-542.

32. Robertson GS, Chadwick DR, Davies J, Rose S, Contractor H, James RF, et al. The effectiveness of components of university of Wisconsin solution in improving human pancreatic islet purification. Transplantation 1994;57(3):346-354.

33. van Suylichem PT, Wolters GH, van Schilfgaarde R. The efficacy of density gradients for islet purification: a comparison of seven density gradients. Transplant Int. 1990;3(3):156-161.

34. Sawada T, Matsumoto I, Nakano M, Kirchhof N, Sutherland DE, Hering BJ. Improved islet yield and function with ductal injection of university of Wisconsin solution before pancreas preservation. Transplantation. 2003; 75 (12): 1965-1969.

35. Kuroda Y, Kawamura T, Suzuki Y, Fujiwara H, Yamamoto K, Yamamoto $\mathrm{M}$, et al. New simple method for cold storage of pancreas with perflurochemical. Diabetes. 1989;38:244-245.

36. Hiraoka K, Trexler A, Eckman E, Stage A, Nevile S, Sageshima J, et al. Successful pancreas preservation before islet isolation by the simplified two layer cold storage method. Transplan Proc. 2001;33(1-2):952-953.

37. Juang JH, Bonner-Weir S, Vacanti JP, Weir GC. Outcome of subcutaneous islet transplantation improved by a apolymer device. Transplant Proc. 1995;27(6):3215-3216.

38. Toledo-Pereyra LH, Bandlien KO, Gordon DA, MacKenzie GH, Reyman TA. Renal subcapsular islet cell transplantation. Diabetes. 1984;33(9):910-914.

39. Mellgren A, Schnell Landström AH, Petersson B, Andersson A. The renal subcapsular site offers better growth conditions for transplanted mouse pancreatic islet cells than the liver or spleen. Diabetologia. 1986;29(9): 670-672.

40. Levy MM, Ketchum RJ, Tomaszewski JE, Naji A, Barker CF, Brayman KL. Intrathymic islet transplantation in the canine: Histological an functional evidence of autologous intrathymic islet engraftment and survival in pancreatectomized recipients. Transplantation. 2002;73(6):842-852.

41. Lakey JR, Warnock GL, Rajotte RV. Intrathymic transplantation of fresh and preserved islets for the induction of a state of unresponsiveness in rats. Transplantation 1996; 61(3): 506-508.

42. Selawry HP, Whittington K. Extended allograft survival of islets grafted into intraabdominally placed testis. Diabetes. 1984;33(4):405-406.

43. Nasr IW, Wang Y, Gao G, Deng S, Diggs L, Rothstein DM, et al. Testicular immune privilege promotes transplantation tolerance by altering the balance between memory and regulatory $\mathrm{T}$ cells. J. Immunol. 2005; 174(10):6161-6168

44. Hara Y, Taniguchi H, Bouike T, Nagata Y, Narutaki K. Insulin content and immunostained insulin in the pancreatic islets allografted in intrathecal space. Transplant Proc. 1993;25(5):2861-2862.
45. Ommaya AK, Atwater I, Yañez A, Szpak-Glasman M, Bacher J, Arriaza C, et al. Lama Glama (the South American Camelid, Llama): A unique model for evaluation of xenogenic islet transplants in a cerebral spinal fluid driven artificial organ. Transplant Proc. 1995;27(6):3304-3307.

46. Gardemann A, Jungermann K, Grosse V, Cossel L, Wohlrab F, Hahn HJ, et al. Intraportal transplantation of pancreatic islets into livers of diabetic rats. Diabetes. 1994;43(11):1345-1352.

47. Kneteman NM, Warnock GL, Evans MG, Nason RW, Rajotte RV. Prolonged function of canine pancreatic fragments autotransplanted to the spleen by venous reflux. Transplantation. 1990;49(4):679-681.

48. Tchervenivanov N, Metrakos P, Kokugawa Y, Rosenberg L. Submucosal transplantation of pancreatic islets. Transplant Proc. 1994;26(2):680681.

49. Behme MT, Dupre J, Stiller CR. Intestinal mesenteric site for islet transplantation. Transplant Proc. 1994;26(2):678-679.

50. Ueki M, Yasunami Y, Ryu S, Ikeda S, Tanaka M. Peritoneal- Omental pouch as a site for islet allotransplantation. Transplant Proc. 1994;26(2):676-677.

51. Lim SM, Li SQ, Poh LH, Lim NK, Seah ML, Heng KK. The rectum as a novel site for islet cell transplantation. Transplantation. 1994;57(2):294-296.

52. Wahoff DC, Hower CD, Sutherland DE, Leone JP, Gores PF. The peritoneal cavity: an alternative site for clinical islet transplantation ?. Transplant Proc. 1994;26(6):3297-3298.

53. de Vos P, Hamel AF, Tatarkiewicz K. Considerations for successful transplantation of encapsulated pancreatic islets. Diabetologia. 2002;45(2):159-173.

54. MonacoAP, Maki T. Islet transplantation using immunoexclusion methods. Transplant Proc 1996,28(4):2042-2045.

55. Jindal RM, Dubernard JM. Towards a specific immunosuppression for pancreas and islet grafts. Clin Transplantation. 2000;14(3):242-245.

56. Shapiro AM, Suarez-Pinzon WL, Power R, Rabinovitch A. Combination therapy with low dose sirolimus and tacrolimus is synergistic in preventing spontanueous and recurrent autoimmune diabetes in nonobese diabetic mice. Diabetologia. 2002;45(2):224-230.

57. International Islet Transplant Registry at The Third Medical Department of the University Medical Centre of Giessen. Germany. Report 2001.

58. Shapiro AM, Lakey JR, Ryan EA, Korbutt GS, Toth E, Warnock GL et al. Islet transplantation in seven patients with Type I Diabetes Mellitus using a glucocorticoid-free immunosuppressive regimen. N Engl J Med. 2000;343(4): 230-238.

59. Ryan EA, Lakey JR, Rajotte RV, Korbutt GS, Kin T, Imes S, et al. Clinical outcomes and insulin secretion after islet transplantation with the Edmonton Protocol. Diabetes. 2001,50(4):710-719.

60. Ryan E.A., Paty B.W., Senior P.A., Bigam D., Alfadhli E., Kneteman N.M. et al Five-year follow-up after clinical islet transplantation. Diabetes. 2005;54(7):2060-2069.

61. Korsgren O, Nilsson B, Berne C, Felldin M, Foss A, Kallen R, et al. Current status of clinical islet transplantation. Transplantation. 2005;79(10):1289-1293.

62. Shapiro AM, Lakey JR, Paty BW, Senior PA, Bigam DL, Ryan EA. Strategic opportunities in clinical islet transplantation. Transplantation. 2005;79(10):1304-1307.

63. Balamurugan AN, Bottino R, Giannoukakis N, Smetanka C. Prospective and challenges of islet transplantation for the therapy of autoimmune diabetes. Pancreas. 2006;32 (3):231-243.

64. Gray DW. Islet transplantation and glucose regulation. World J Surg. 2001;25(4):497-502.

65. Toomey P, Chadwick DR, Contractor H, Bell PR, James RF, London NJ. Porcine islet isolation: prospective comparison of automated and manual methods of pancreatic collagenase digestion. $\mathrm{Br} \mathrm{J}$ Surg. 1993;80(2):240-243

66. Toso C, Brandhorst D, Oberholzer J, Triponez F, Bühler L, Morel P. Isolation of adult porcine islets of Langerhans. Cell Transplantation. 2000;9(3):297-305.

Correspondencia autora: Dra. V. Gómez Dos Santos

Unidad de Urología. Fundación Hospital Alcorcón

Budapest, 1 - 28922 Alcorcón (Madrid). Tel.: 916219400

E-mail autora: urologo@tiscali.es

Información artículo: Original 